Article

\title{
High Performance Anti-Corrosion Coatings of Poly (Vinyl Butyral) Composites with Poly $N$-(vinyl)pyrrole and Carbon Black Nanoparticles
}

\author{
Lu Hao ${ }^{1,2}$, Guowei Lv ${ }^{1}$, Yaqian Zhou ${ }^{1}$, Kaiming Zhu ${ }^{1}$, Mochen Dong ${ }^{1}$, Yuhang Liu ${ }^{3}$ and \\ Demei Yu ${ }^{1,2, *}$ \\ 1 Department of Applied Chemistry, School of Science, MOE Key Laboratory for Non-Equilibrium Synthesis \\ and Modulation of Condensed Matter, Xi'an Jiaotong University, Xi'an 710049, China; \\ haoluatssd@163.com (L.H.); guoweilv@xjtu.edu.cn (G.L.); zhoupolymer@163.com (Y.Z.); \\ zkm1994@stu.xjtu.edu.cn (K.Z.); mcdong@stu.xjtu.edu.cn (M.D.) \\ 2 State Key Laboratory of Electrical Insulation and Power Equipments, Xi'an Jiaotong University, \\ Xi'an 710049, China \\ 3 Department of Chemistry, Hong Kong University of Science and Technology, Hong Kong 999077, China; \\ yliuay@outlook.com \\ * Correspondence: dmyu@mail.xjtu.edu.cn; Tel.: +86-29-82668559
}

Received: 12 October 2018; Accepted: 14 November 2018; Published: 17 November 2018

\begin{abstract}
Zinc is widely used in battery negative electrodes and steel coatings for automotive industries. The anti-corrosion property of zinc is the most important factor determining the performance and lifetime of the products. In this paper, both size-controlled poly $\mathrm{N}$-(vinyl)pyrrole (PNVPY) nanoparticles and carbon black (CB) nanoparticles were compounded with poly (vinyl butyral) (PVB) binder developing a series of composite coatings covered on the zinc substrates using a spin-coating technique. The morphologies of the surface and cross section of the PNVPY/CB/PVB coatings indicate that the PNVPY and CB nanoparticles are uniformly distributed in the matrix. The corrosion resistance of the composite coatings was tested by electrochemical impedance spectroscopy (EIS) and potentiodynamic polarization in a $3.5 \% \mathrm{NaCl}$ solution. It is found that the coating with $1.9 \mathrm{wt} . \%$ PNVPY and $2.3 \mathrm{wt} . \%$ CB nanoparticles shows a remarkably high resistance value $\left(R_{c}\right)$ and corrosion protection efficiency $(99.99 \%)$. Meanwhile, the immersion results also reveal its superior corrosion resistance. It is considered that the nanoscale dispersion of PNVPY and carbon in PVB matrix and the strong interface action between the nanoparticles and PVB result in the uniform microstructure of the composites which endues the superior corrosion properties of the coatings.
\end{abstract}

Keywords: carbon black; poly $N$-(vinyl)pyrrole nanoparticles; corrosion resistant

\section{Introduction}

Metals corrosion is considered a serious problem in modern civilization [1], especially in the field of the metallurgical and electronic industries. As one of the most popular metals, zinc is widely used in battery negative electrodes and steel coatings for automotive industries. The anti-corrosion property of zinc is the most important factor determining the performance and lifetime of the products. Several strategies have been developed to prepare zinc protective layers. Aramaki's group prepared a protective film by immersing a zinc electrode in a $\mathrm{Ce}\left(\mathrm{NO}_{3}\right)_{3}$ aqueous solution and detected in an aerated $0.5 \mathrm{M} \mathrm{NaCl}$ solution by polarization measurement. The protective efficiency of the film against zinc corrosion was more than 91\% [2]. Magalhães's group characterized the morphology and electrochemical features of zinc surfaces converted in acid baths of sodium molybdate by immersion. Corrosion resistance was tested under different conditions. The conversion coatings with $0.3 \mathrm{M}$ 
molybdate baths at $\mathrm{pH} 3$ acidified with phosphoric acid for $10 \mathrm{~min}$ provided the best performance [3]. Although these methods can effectively prevent zinc from corrosion, a little pitting corrosion also occurred on the surface of coating and the performance sometimes was lower [4,5].

Conducting polymers (CPs) are one of the most promising organic corrosion inhibitors as anti-corrosive coating materials owing to their excellent anticorrosion ability that acts as both physical and electronic barriers [6-8]. Furthermore, defect-free coatings with uniform coverage may be obtained when the coatings are doped with CPs. DeBerry [9] firstly reported that conductive polymer polyaniline (PANI) promoted the formation of a passive surface on stainless steel and then made stainless steel anti-corrosive in sulfuric acid solution in the 1980s. Syed et al. [10] fabricated polyaniline-polyacrylic acid/polyethyleneimine (PANI-PAA/PEI) composite coatings with a multilayer structure for corrosion protection of 316 stainless steels (316SS). It was found that the PANI-PAA/PEI coating with an optimized layer number of 20 showed improved corrosion protection.

Among the group of conducting polymers, such as polyaniline, polythiophene and polypyrrole, polypyrrole (PPy) and its derivatives are widely studied due to their environmental stability, relatively high conductivity and ease of synthesis by chemical and electrochemical methods [11-13]. Ryu et al. [14] prepared a dense polypyrrole film on 55\% Al-Zn-coated steel in an acidic tartrate solution by the electrochemical method. The PPy layer can maintain passivation of steel in a $3.5 \mathrm{wt} . \% \mathrm{NaCl}$ aqueous solution and protect the steel for several hours. Ruhi et al. [15] synthesized polypyrrole/ $\mathrm{SiO}_{2}$ composite by chemical oxidative polymerization of pyrrole using $\mathrm{FeCl}_{3}$ as an oxidant. The results of electrochemistry analysis exhibited a remarkably high corrosion protection efficiency of epoxy coatings with polymer composite in $3.5 \mathrm{wt} . \% \mathrm{NaCl}$ solution.

Although there are positive reports on the application of PPy in corrosion protection, PPy still has some limitations when used in anti-corrosion coatings. Firstly, PPy has poor solubility in many common solvents due to its rigid molecule structure. As a result, it is difficult to disperse PPy well into the matrix, causing poor antiseptic performance. Secondly, there are always metal ion integrities in the preparation of PPy by conventional methods, resulting in the limitation for its application, especially for corrosion protection. Thirdly, PPy fails to protect coatings when larger defects exist [16]. Usually, preparing composite coatings by adding PPy is in favor of the formation of a passive metal surface at the coating/metal interface [16-18]. However, an insulating layer will be formed at the PPy and metal interface when PPy is applied on non-noble metal surfaces, resulting in a low potential caused by electronic decoupling at the interface, which is unfavorable for protracted protection of metal $[19,20]$. To avoid such problem, CB can be employed as conductive spacers to ensure the electronic contact at the $\mathrm{CPs} /$ metal interface [21].

In our previous study, a serious of well-dispersed sulfate doped PPy and its derivative nanoparticles were synthesized by a green method, providing a chance to enlarge their application [22,23]. In this work, both PNVPY and carbon black nanoparticles are filled in poly (vinyl butyral) (PVB) matrix with different contents forming a series of composite coatings. The coatings are then spun on the zinc substrate as a corrosion protection. The electrochemical properties of bare and coated zinc are investigated by open-circuit voltage (OCP), electrochemical impedance spectroscopy (EIS) and potentiodynamic polarization. Meanwhile, the anticorrosive properties of the composite coatings with different composition of PNVPY/CB/PVB are discussed.

\section{Experimental}

\subsection{Materials}

Pure zinc sheets with a thickness of $1 \mathrm{~mm}$ were supplied by China New Metal Materials Technology Co., Ltd. (Zhangjiagang, China). The zinc sheets were cut into small pieces with an exposed surface of $20 \times 10 \mathrm{~mm}^{2}$ using wire electrical discharge machining for corrosion experiments. The surface of the zinc was polished with 600,800 and 1000 grit SiC paper, respectively. Then, they were immersed in ethanol using an ultrasonic bath for $20 \mathrm{~min}$ and dried in a nitrogen stream. 
Conductive CB (super C65) and PVB were purchased from Timcal Company (Shanghai, China) and Sinopharm Chemical Reagent Co. Ltd. (Beijing, China), respectively. All the solvents were obtained from Tianli Chemical Reagent Co. (Tianjin, China) without any pretreatment. A MODEL KW-4A Spin Coater (Siyouyen Ltd., Beijing, China) was used for distributing the DMF solution of PNVPY/CB/PVB composites evenly on zinc substrate. The electrochemistry analysis was recorded by a CHI760 electrochemical workstation (CH instruments Ltd., Shanghai, China).

\subsection{The Synthesis of PNVPY Nanoparticles}

Well-dispersed sulfate doped PNVPY nanoparticles for the coating uses were prepared via UV-catalytic polymerization with $\mathrm{H}_{2} \mathrm{O}_{2}$ as an oxidant and polyvinyl pyrrolidone (PVP) as a stabilizer, referred to as the green synthesis method developed by our group [23]. The synthesis process was shown as follows: A certain amount of $N$-(vinyl)pyrrole (NVPY) was added to $30 \mathrm{~mL}$ PVP aqueous solution. After magnetic stirring ( $800 \mathrm{rpm}$ ) for $10 \mathrm{~min}$, an additional $30 \mathrm{~mL}$ aqueous solution mixture of $\mathrm{H}_{2} \mathrm{O}_{2}$ and $\mathrm{H}_{2} \mathrm{SO}_{4}$ was introduced to the above solution. Under $\mathrm{UV}$ irradiation (253.7 nm), the polymerization reaction was initiated and proceeded for $5 \mathrm{~h}$ at room temperature. The PNVPY nanoparticles were obtained at a centrifugal speed of $12,000 \mathrm{rpm}$ for $10 \mathrm{~min}$.

\subsection{The Preparation of Composite Coating and Coated Zinc}

The preparation process of anti-corrosion coatings is shown as follows: PNVPY nanoparticles with different concentrations (1.9 wt.\%, $6.4 \mathrm{wt} . \%$ and $8.9 \mathrm{wt} . \%)$ were added in $1.6 \mathrm{~mL}$ $\mathrm{N}, \mathrm{N}$-dimethylformamide (DMF) and stirred thoroughly by magnetic stirrer for $30 \mathrm{~min}$ at room temperature. Later on, CB particles were dispersed in the above solution and the mixture was treated with ultrasonic for $10 \mathrm{~min}$. At last, a certain amount of PVB was added in and stirred for $4 \mathrm{~h}$ at $35^{\circ} \mathrm{C}$. Then, the composite dispersions were spin-coated directly on zinc with a speed of $2500 \mathrm{rpm}$ and dried at $60^{\circ} \mathrm{C}$ for $2 \mathrm{~h}$. The spin time was adjusted to maintain the same thickness of the coating of different samples. The dispersion of $13.9 \mathrm{wt} . \%$ PVB dissolved in $1.6 \mathrm{~mL}$ DMF was spin-coated once again at the same spin speed on the composite films and dried at $60^{\circ} \mathrm{C}$ for $2 \mathrm{~h}$. The thickness of the coatings here was maintained at about $7 \mu \mathrm{m}$ according to the similar system investigated by Bai et al. [21] to compare the anti-corrosion properties of the coatings. The concentrations of composite coatings with different ratio of PNVPY/CB/PVB are listed in Table 1.

Table 1. The concentration of composite coatings with different ratios of PNVPY/CB/PVB.

\begin{tabular}{cccc}
\hline Sample & PNVPY (wt.\%) & CB (wt.\%) & PVB (wt.\%) \\
\hline 1 & 0 & 0 & 100 \\
2 & 2 & 0 & 98 \\
3 & 0 & 2.3 & 97.7 \\
4 & 1.9 & 2.3 & 95.8 \\
5 & 6.4 & 2.2 & 91.4 \\
6 & 8.9 & 2.1 & 89 \\
\hline
\end{tabular}

\subsection{Characterization Methods}

The morphology of PNVPY was observed by dropping the diluted reaction solution of PNVPY directly onto the silicon wafer using a JSM 7000M scanning electron microscope (SEM) (JEOL Ltd., Tokyo, Japan) as soon as the polymerization of NVPY finished. The particle size and size distributions of PNVPY particles were analyzed by the dynamic lighting scattering (DLS) technique using a Nano-ZS90 Malvern instrument (Malvern Instruments Ltd., Worcestershire, UK). The tests were performed by dispersing the PNVPY powders into several solvents. The morphologies of PNVPY powders dissolved in DMF were observed by a JEM-2100 transmission electron microscope (TEM) (JEOL Ltd., Tokyo, Japan ). The CB nanoparticles were added to ethanol with ultrasonic treatment, then dropped onto the silicon wafer for SEM (JSM 7000M) observation. The PNVPY/CB/PVB composite 
coating film exfoliated from the coated zinc was quenched in liquid nitrogen. Both the upper surface and cross section were observed (JSM 7000M).

The electrochemistry analysis was performed in a single compartment three electrodes cell (bare zinc and coated zinc as the working electrode with an exposed area of $2 \mathrm{~cm}^{2}$, a platinum plate as the counter electrode and a saturated calomel electrode as the reference electrode) at room temperature in a $3.5 \% \mathrm{NaCl}$ solution. The open circuit potential (Eocp) measurements were performed for $400 \mathrm{~s}$ after the samples were immersed in 3.5\% $\mathrm{NaCl}$ solution for $30 \mathrm{~min}$. Electrochemical Impedance Spectroscopy (EIS) data was recorded in the frequency ranging from $100 \mathrm{kHz}$ to $100 \mathrm{mHz}$ by immersing the electrodes into the $3.5 \% \mathrm{NaCl}$ solution. The potentiodynamic polarization curves were obtained starting from the open circuit potential (OCP) with a scan rate of $1 \mathrm{mV} \mathrm{s}^{-1}$ and varying the potential to $300 \mathrm{mV}$ in a set of experiments (anodic region of the Tafel plot) and to $300 \mathrm{mV}$ in another set of experiments (cathodic region of the Tafel plot). Oxygen was not removed from the $\mathrm{NaCl}$ solution before these experiments.

\section{Results and Discussion}

\subsection{Characterization of PNVPY Nanoparticles}

The structure characteristic and the morphology of sulfate doped PNVPY were investigated as shown in Figure 1. It can be seen from Figure 1a that the absorption peaks at 1551 and $1487 \mathrm{~cm}^{-1}$ correspond to the aromatic ring in PNVPY. The absorptions at 1660 and $3099 \mathrm{~cm}^{-1}$ represent the double bond. The peak that appeared at $781 \mathrm{~cm}^{-1}$ is attributed to the a-substituted five-membered heterocyclic ring compound [24]. The absorption bands at 1375 and $1087 \mathrm{~cm}^{-1}$ correspond to asymmetric and symmetric $\mathrm{S}(=\mathrm{O})_{2}$ stretching $[25,26]$. The morphology of PNVPY was observed by dropping the diluted reaction solution of PNVPY directly onto the silicon wafer as soon as the polymerization of NVPY finished. It can be seen in Figure $1 \mathrm{~b}$ that PNVPY nanoparticles are spherical with diameters ranging from $22 \mathrm{~nm}$ to $58 \mathrm{~nm}$, and the average size is around $38 \mathrm{~nm}$.
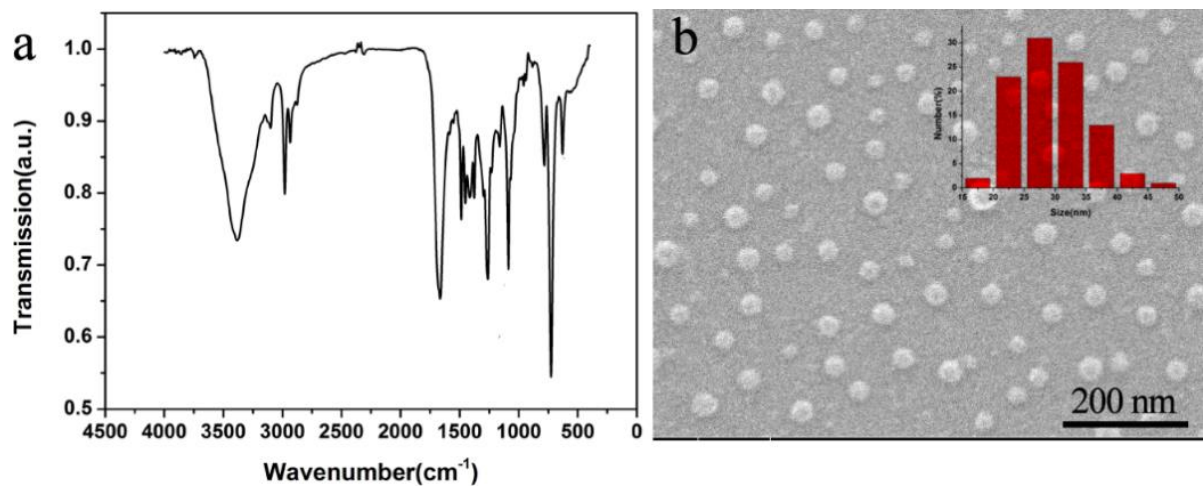

Figure 1. (a) Fourier Transform infrared spectroscopy and (b) morphologies of the PNVPY nanoparticle.

\subsection{Morphology Analysis of Coatings}

The poor dispersibility of conductive polymers in versatile organic solvents restrains their applications on spin-coating. In our study, PNVPY powders can be dispersed well in water, tetrahydrofuran (THF), chloroform (CLF), and N,N-dimethylformamide (DMF) (inset of Figure 2b). The size distribution of PNVPY powders in several solvents is measured by DLS, as shown in Figure 2a. It was found that the size of PNVPY particles decreases gradually from about $300 \mathrm{~nm}$ to $1 \mathrm{~nm}$ in $\mathrm{H}_{2} \mathrm{O}$, CLF, THF and DMF, respectively. It can be attributed to the aggregation of PNVPY particles, especially in $\mathrm{H}_{2} \mathrm{O}, \mathrm{CLF}$, THF. This phenomenon also can be verified by the decrease in the value of Derived Count Rate in $\mathrm{H}_{2} \mathrm{O}, \mathrm{CLF}, \mathrm{THF}$ and DMF, respectively, as shown in Figure 2b. Moreover, the average size of particles in DMF is about $30 \mathrm{~nm}$, which is in accordance with its TEM photograph (the spherical PNVPY particle with an average size of about $30 \mathrm{~nm}$ ), as shown in Figure 2c. Therefore, DMF is a favorable solvent to disperse PNVPY particles for the preparation of the composite coatings. The SEM 
micrograph of CB is shown in Figure 2d. It is clear that the CB particles are grouped into chains, forming spatial network channel-like grape clusters. The mesh chains are stacked tightly, leading to a large specific surface area and high load of CB particles per unit of mass, which facilitated the formation of the chain conduction structure in the polymer.
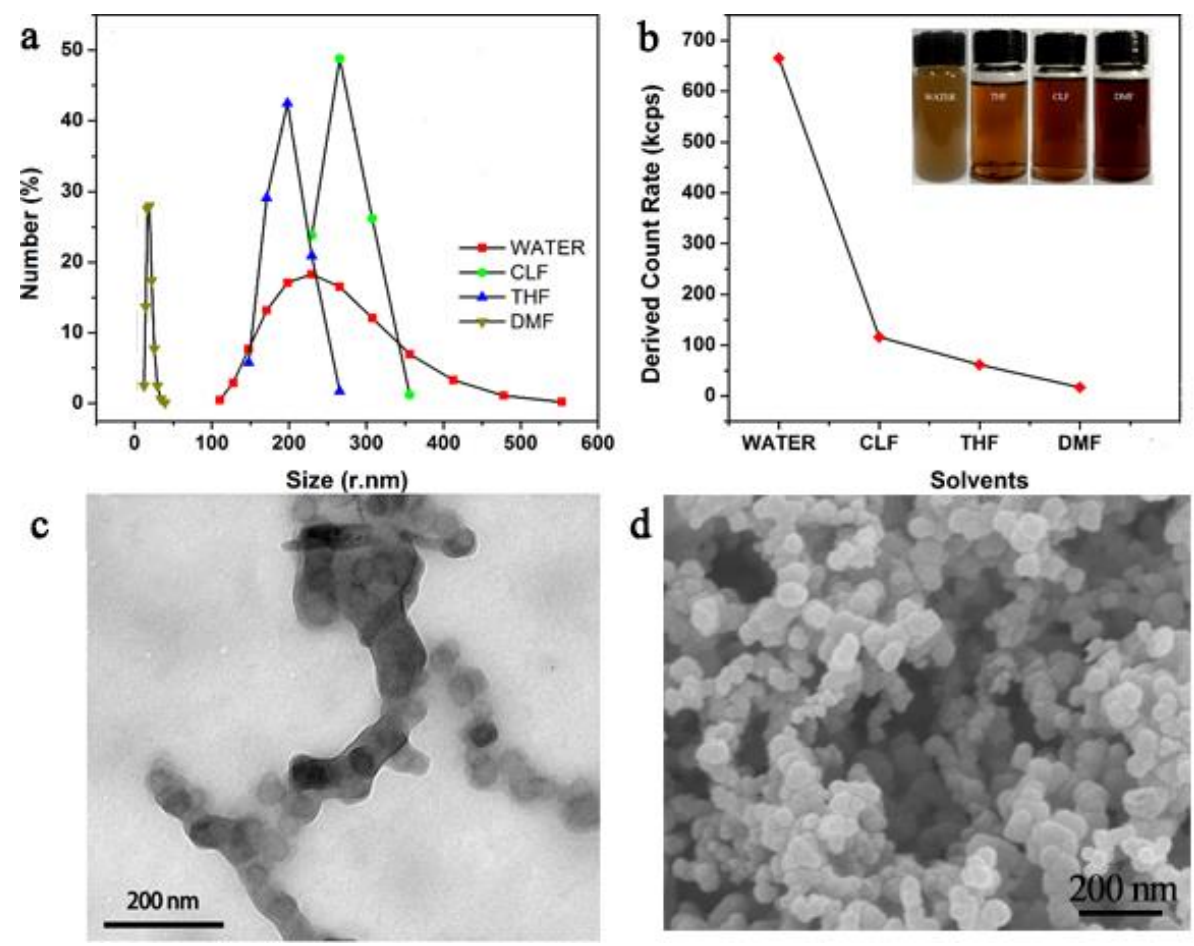

Figure 2. (a) The size distribution of PNVPY particles in different solvents. (b) The value of Derived Count Rate of PNVPY particles dispersed in different solvents (solution concentration $=0.81 \mathrm{~g} / \mathrm{L}$ ). The inset is the photos of PNVPY particles dispersed in different solvents. (c) Transmission electron microscope (TEM) photograph of PNVPY particles obtained from its $N, N$-dimethylformamide (DMF) dispersion. (d) Scanning electron microscope (SEM) photograph of CB particles obtained from its ethanol dispersion.

The morphologies of the upper surface and cross section of the PNVPY/CB/PVB coating exfoliation from the coated zinc (Sample 4) are shown in Figure 3. The film exhibits a relatively flat surface with many granules and rare aggregation of PNVPY and CB as observed from Figure 3a. As blended with PNVPY, part of the CB nanoparticles may act as a bridge to ensure the electronic connection between the PNVPY nanoparticles in the coating. Meanwhile, as can be seen in Figure 3b, there are more nanoparticles near the internal surface contact with zinc.
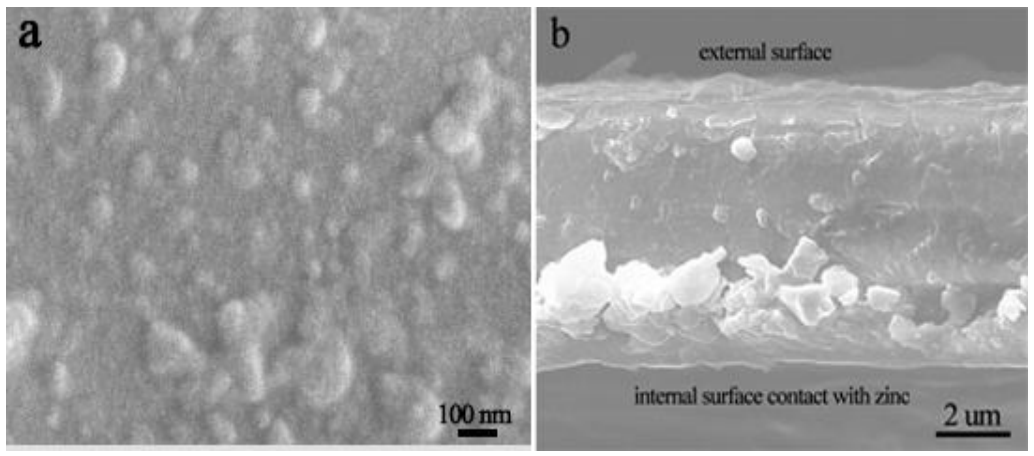

Figure 3. (a) Surface and (b) cross-section photos of the PNVPY/CB/PVP film exfoliated from coated zinc. 


\subsection{Corrosion Studies by Electrochemical Method}

\subsubsection{Open Circuit Potential (OCP) Measurement}

Figure 4 illustrates the variation of OCP at different times for coated and uncoated zinc immersed in a $3.5 \% \mathrm{NaCl}$ solution. The trends of OCP variation with time of bare zinc exhibit a gentle shift of potential towards the cathodic direction. The OCP of the bare zinc is about $-1079 \mathrm{mV}$ vs. SCE (Saturated calomel electrode) at the end of the immersion time. The OCP of pure PVB coating (Sample 1) shifts gradually towards the anodic direction and maintains at around $-1059 \mathrm{mV}$ (SCE). Moreover, the PVB/CB composite coating (Sample 3) maintains a small fluctuation at about $-1057 \mathrm{mV}$. In contrast, the OCP levels of the zinc with PVB/CB/PNVPY composite coating of dosage 1.9\% (Sample 4), 6.4\% (Sample 5) and 8.9\% (Sample 6) are higher than bare zinc and Sample-3. Especially, the OCP level of Sample 5 is as high as about $-1010 \mathrm{mV}$, indicating it has a potentially favorable anti-corrosion effect on zinc.

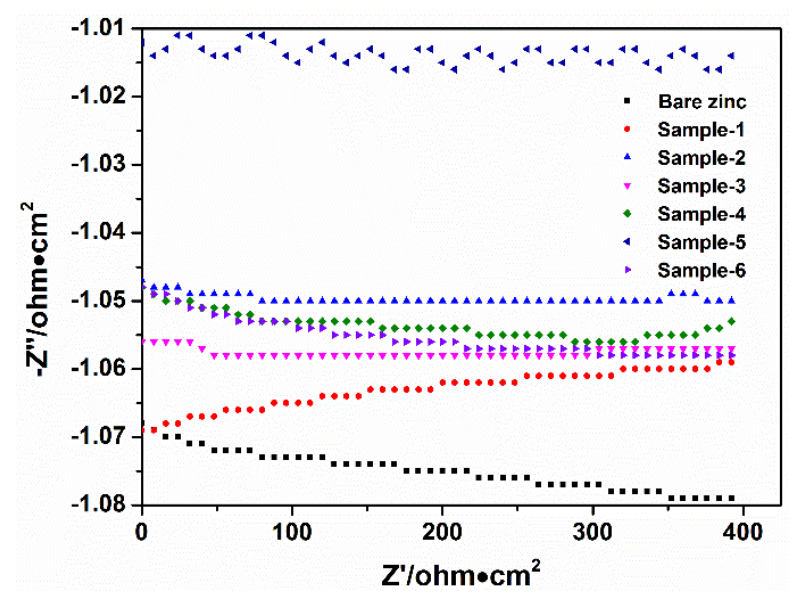

Figure 4. Open circuit potential (OCP) variation with time for samples immersed in a $3.5 \% \mathrm{NaCl}$ solution at room temperature $\left(25^{\circ} \mathrm{C}\right)$.

\subsubsection{Electrochemical Impedance Spectroscopy}

Electrochemical impedance spectroscopy (EIS) is a useful and non-destructive method in studying the corrosion mechanism. Figure 5 shows the EIS of all samples. The Nyquist plots obtained from bare zinc and coated zinc in the condition of open circuit potential are displayed in Figure 5a. The Nyquist plot of bare zinc (Figure $5 \mathrm{~b}$ ) shows a small arc with the lowest impedance value as compared to other specimens. It can be seen in Figure $5 c$ that the specimen of pure PVB coated zinc has a larger impedance value than bare zinc. The impedance value of Sample 2 increased by an order of magnitude due to the addition of PNVPY (1.9 wt.\%) to the PVB coating (Figure 5d). It is considered that the Fermi-level misalignment between zinc and the conductive polymer may cause an improved corrosion protection on zinc only by a passive and not by an active function [4]. Moreover, an obvious high impedance value of the zinc coated with PNVPY/CB/PVB composite coating appears as shown in Figure 5a (Sample 4, Sample 5 and Sample 6). It indicates that the addition of CB matches Fermi resonance between conducting polymers and the surface of the zinc. Interestingly, the impedance value of the specimen does not increase with the increase in PNVPY dosage from $6.4 \mathrm{wt} . \%$ to $8.9 \mathrm{wt} . \%$. There is a significant reduction of the radius of the semicircle when the PNVPY content increases to $6.4 \mathrm{wt} . \%$ and $8.9 \mathrm{wt} . \%$. It is inferred that the proportion of the CB is reduced in the composite when the PNVPY content increases, which cannot solve the problem of electronical decoupling effectively. 

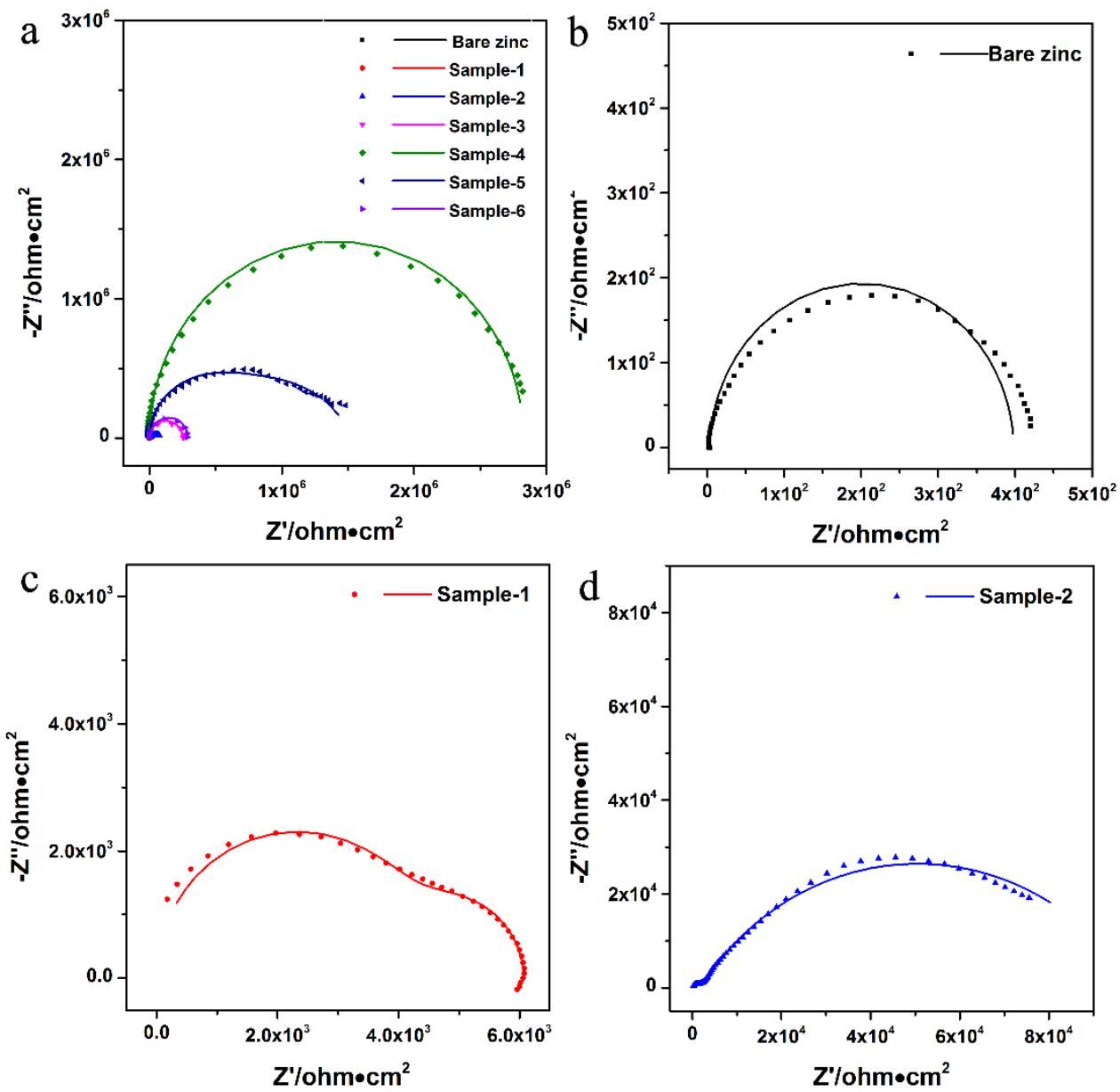

Figure 5. (a-d) Nyquist plots of electrochemical impedance spectroscopy (EIS) (dots) and fits of a ZsimpWin (version 3.60, lines) operated immersed in a 3.5\% NaCl solution at room temperature $\left(25^{\circ} \mathrm{C}\right)$. The $\mathrm{R}^{2}$ values from EIS data of bare zinc, Sample 1, Sample 2, Sample 3, Sample 4, Sample 5 and Sample 6 were $0.9625,0.9376,0.9967,0.9025,0,9499$ and 0.9448 , respectively.

The equivalent circuits are shown in Figure 6. The corresponding electrochemical parameters extracted by fitting EIS plots with the Zsimpwin program are summarized in Table 2. CPE is a constant phase element, and $\mathrm{CPE}_{1}$ and $\mathrm{CPE}_{2}$ are used in place of coating capacitance and double-layer capacitance in order to give more accurate fits to the experimental results. $R_{c}$ is attributed to the pore resistance and signifies the performance of the surface coating $[15,27]$, which is inversely proportional to the defects (pores) in a film. Its value can be taken as a measure of the porosity and the degree of degradation of a coating film.

The $R_{c}$ values for different samples are shown in Table 2. A low $R_{c}\left(395 \Omega \mathrm{cm}^{2}\right)$ for bare zinc indicates the presence of a porous layer of corrosion product on its surface. For this reason, chloride ions continually diffuse to the metal surface, causing a decreased $R_{c}$. The measured $R_{c}$ of zinc coated with pure PVB coating is almost one order of magnitude higher than the uncoated zinc because of the physical barrier effect. The $R_{c}$ increases more than one order of magnitude for Sample 3 as compared to bare zinc. Sample 4 shows the highest $R_{c}\left(2.71 \times 10^{6}\right)$ among the specimens tested, indicating its superior barrier property. Moreover, the value of $R_{c}$ decreases when the content of PNVPY increases from $6.4 \mathrm{wt} . \%$ to $8.9 \mathrm{wt} . \%$ in the composite coatings. 
a

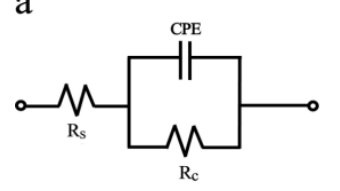

b

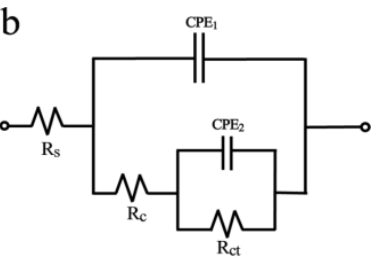

Figure 6. Equivalent circuit model of (a) uncoated zinc and (b) coated zinc. $\mathrm{CPE}_{1}$ and $\mathrm{CPE}_{2}$ are coating film capacitance and its double-layer capacitance in $3.5 \% \mathrm{NaCl}$ solution, respectively. $R_{\mathrm{s}}, R_{c}$ and $R_{c t}$ are solution resistance, coating resistance and charge transfer resistance.

Table 2. Impedance data for bare zinc and coated zinc with the composite coatings in $3.5 \% \mathrm{NaCl}$.

\begin{tabular}{ccccccc}
\hline Sample & $\mathbf{C P E}_{\mathbf{1}}$ & $\mathbf{n}_{\mathbf{1}}$ & $\mathbf{R}_{\mathbf{c}}\left(\mathbf{\Omega} \mathbf{~ c m}^{\mathbf{2}}\right)$ & $\mathbf{C P E}_{\mathbf{2}}$ & $\mathbf{n}_{\mathbf{2}}$ & $\mathbf{R}_{\mathbf{c t}}\left(\boldsymbol{\Omega} \mathbf{c m}^{\mathbf{2}}\right)$ \\
\hline Bare zinc & $1.48 \times 10^{5} \pm 5.8 \%$ & $0.98 \pm 2.0 \%$ & $395 \pm 5.4 \%$ & - & - & \\
1 & $1.51 \times 10^{9} \pm 1.6 \%$ & $0.95 \pm 2.0 \%$ & $4.59 \times 10^{3} \pm 2.9 \%$ & $5.21 \times 10^{8} \pm 1.7 \%$ & $0.98 \pm 0.8 \%$ & $1.48 \times 10^{3} \pm 3.5 \%$ \\
2 & $1.54 \times 10^{8} \pm 4.0 \%$ & $0.88 \pm 5.2 \%$ & $3.89 \times 10^{3} \pm 2.8 \%$ & $2.24 \times 10^{6} \pm 2.9 \%$ & $0.63 \pm 3.3 \%$ & $8.94 \times 10^{4} \pm 4.4 \%$ \\
3 & $4.24 \times 10^{10} \pm 3.6 \%$ & $0.96 \pm 4.2 \%$ & $2.16 \times 10^{5} \pm 5.5 \%$ & $3.08 \times 10^{6} \pm 2.1 \%$ & $0.66 \pm 5.8 \%$ & $2.86 \times 10^{4} \pm 3.9 \%$ \\
4 & $3.55 \times 10^{10} \pm 2.3 \%$ & $0.95 \pm 3.5 \%$ & $2.71 \times 10^{6} \pm 2.0 \%$ & $1.57 \times 10^{7} \pm 1.8 \%$ & $0.78 \pm 4.6 \%$ & $2.12 \times 10^{5} \pm 2.7 \%$ \\
5 & $1.67 \times 10^{10} \pm 2.2 \%$ & $0.94 \pm 3.6 \%$ & $1.65 \times 10^{6} \pm 1.9 \%$ & $7.27 \times 10^{9} \pm 4.0 \%$ & $0.76 \pm 2.5 \%$ & $1.42 \times 10^{5} \pm 3.1 \%$ \\
6 & $3.61 \times 10^{10} \pm 5.0 \%$ & $0.92 \pm 3.4 \%$ & $2.65 \times 10^{5} \pm 6.1 \%$ & $6.26 \times 10^{6} \pm 2.5 \%$ & $0.82 \pm 4.3 \%$ & $2.60 \times 10^{4} \pm 2.7 \%$ \\
\hline
\end{tabular}

\subsubsection{Potentiodynamic Polarization}

The potentiodynamic polarization method was also employed in order to compare the corrosion prevention ability of various polymer coatings on $\left.\mathrm{Zn} \mathrm{[28].} \mathrm{A} \mathrm{higher} \mathrm{corrosion} \mathrm{potential} \mathrm{(} \mathrm{E}_{\mathrm{corr}}\right)$ and a lower corrosion current $\left(\mathrm{i}_{\text {corr }}\right)$ is advantageous to effective anti-corrosion coating. Figure 7 shows the potentiodynamic polarization curves of samples immersed in a $3.5 \% \mathrm{NaCl}$ solution at room temperature $\left(25^{\circ} \mathrm{C}\right)$. Meanwhile, to reveal the effect of conductive filler on the anti-corrosion behavior of the coating in detail, the electrochemical parameters obtained by Tafel extrapolation of the curves in Figure 7 are listed in Table 3. As can be seen from Figure 7 and Table 3, the corrosion current density ( $\mathrm{i}_{\text {corr }}$ ) of Sample $1\left(\mathrm{i}_{\text {corr }}=8.278 \times 10^{-6} \mathrm{~A} / \mathrm{cm}^{2}\right)$ is almost three orders of magnitude less than the bare zinc. It is reasonable that polymer coatings have good resistance towards diffusive ions [29]. When the carbon black is added as the inorganic filler to the PVB coating $\left(i_{\text {corr }}=2.231 \times 10^{-7} \mathrm{~A} / \mathrm{cm}^{2}\right)$, it acts as a mechanical integrity significantly improving the physical barrier ability against the penetration of aggressive chloride ions, which is the same function as other conventional coatings/paints that inhibit the penetration of ions, protecting the metal surface [30-32]. Meanwhile, the addition of conductive $\mathrm{CB}$ avoids forming an insulating layer that will cause electrical decoupling (Fermi-level misalignment) at the PNVPY/metal interface and has a seemingly low potential (Sample 3) [21]. The $\mathrm{i}_{\text {corr }}$ of the coated zinc further decreased to $1.245 \times 10^{-9} \mathrm{~A} / \mathrm{cm}^{2}, 5.349 \times 10^{-9} \mathrm{~A} / \mathrm{cm}^{2}$ and $1.924 \times 10^{-7} \mathrm{~A} / \mathrm{cm}^{2}$, when the zinc was spin-coated with the composite coatings of PNVPY $/ \mathrm{CB} / \mathrm{PVB}$ containing PNVPY nanoparticles of $1.9 \mathrm{wt} . \%, 6.4 \mathrm{wt} . \%$ and $8.9 \mathrm{wt} . \%$, respectively. In particular, Sample 4 has extremely high $\mathrm{E}_{\text {corr }}(-0.821 \mathrm{~V})$ and low $\mathrm{i}_{\text {corr }}\left(5.349 \times 10^{-9} \mathrm{~A} / \mathrm{cm}^{2}\right)$, showing excellent corrosion protection efficiency. In addition, the corrosion current increases with the increase of PNVPY content, which demonstrates excessive conducting polymers added in coatings are not good for anti-corrosion. The corrosion protection efficiency (\% P.E.) is defined by the measured $\mathrm{i}_{\text {corr }}$ \{corrosion current density of uncoated $\mathrm{Zn}\left(\mathrm{i}^{0}{ }_{\text {corr }}\right)$ and the corrosion current density of coated $\mathrm{Zn}\left(\mathrm{i}^{\mathrm{c}}\right.$ corr $\left.)\right\}$ values in the Equation (1) [20].

$$
\% \text { P.E. }=\left(\mathrm{i}^{0}{ }_{\text {corr }}-\mathrm{i}^{\mathrm{c}} \text { corr }\right) / \mathrm{i}^{0}{ }_{\text {corr }} \times 100
$$

The highest calculated \% P.E. of Sample 4 (99.99\%) shows outstanding corrosion resistance, which is coincident with the result of lowest corrosion current. The results were better than those reported in other literature [2,33-35]. 


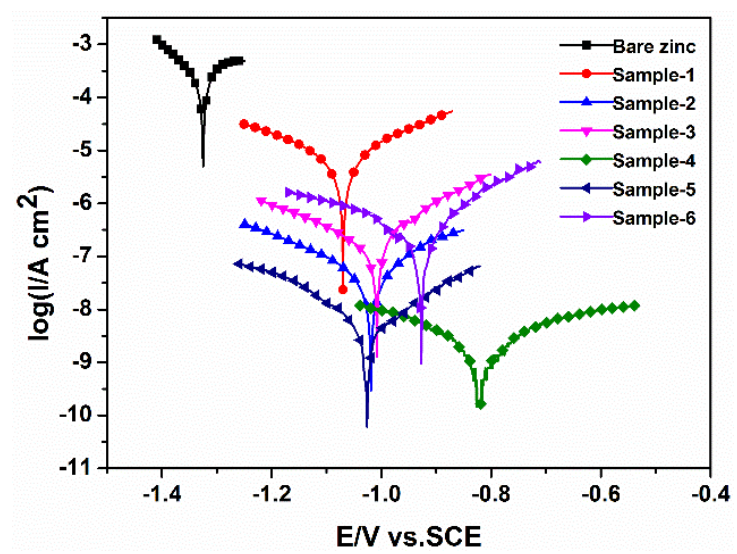

Figure 7. Potentiodynamic polarization curves of samples immersed in a $3.5 \% \mathrm{NaCl}$ solution at room temperature $\left(25^{\circ} \mathrm{C}\right)$.

Table 3. Electrochemical parameters obtained by Tafel extrapolation in $3.5 \% \mathrm{NaCl}$ solution.

\begin{tabular}{cccc}
\hline Sample & $\mathbf{E}_{\text {corr }}(\mathbf{V})$ & $\mathbf{i}_{\text {corr }}\left(\mathbf{A} / \mathbf{c m}^{\mathbf{2}}\right)$ & \% P.E. \\
\hline Bare zinc & $-1.320 \pm 4.3 \%$ & $2.665 \times 10^{-4} \pm 3.6 \%$ & ------- \\
1 & $-1.069 \pm 3.5 \%$ & $8.278 \times 10^{-6} \pm 6.1 \%$ & 96.89 \\
2 & $-1.015 \pm 3.8 \%$ & $4.868 \times 10^{-8} \pm 6.1 \%$ & 99.98 \\
3 & $-1.009 \pm 6.6 \%$ & $2.231 \times 10^{-7} \pm 3.7 \%$ & 99.92 \\
4 & $-0.821 \pm 5.0 \%$ & $1.245 \times 10^{-9} \pm 5.2 \%$ & 99.99 \\
5 & $-1.030 \pm 7.6 \%$ & $5.349 \times 10^{-9} \pm 6.3 \%$ & 99.98 \\
6 & $-0.930 \pm 4.9 \%$ & $1.924 \times 10^{-7} \pm 4.0 \%$ & 99.93 \\
\hline
\end{tabular}

\subsection{Immersion Test of the Coatings without Defect}

Three samples were chosen to assess corrosion protection performance for a long time by immersing them in 3.5\% NaCl solution, including bare zinc, pure PVB coated zinc (Sample 1) and PVB blended with 1.9 wt.\% PNVPY and 2.3 wt.\% CB coated zinc (Sample 4). Figure 8 clearly shows that uncoated zinc suffers a severe corrosion, while the Sample 1 nearly has no significant change after $48 \mathrm{~h}$. However, a serious corrosion appears on the surface after $168 \mathrm{~h}$, as a consequence of the penetration of corrosive ion into the metal surface, damaging the physical barrier. Sample 4 shows no significant change after $168 \mathrm{~h}$ in $3.5 \% \mathrm{NaCl}$, indicating its remarkably high corrosion protection. Consequently, Sample 4 has optimum performance against corrosive in seawater conditions. 
a
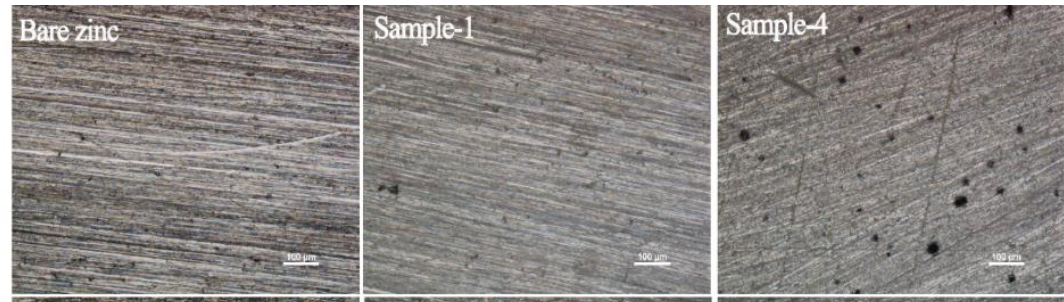

b
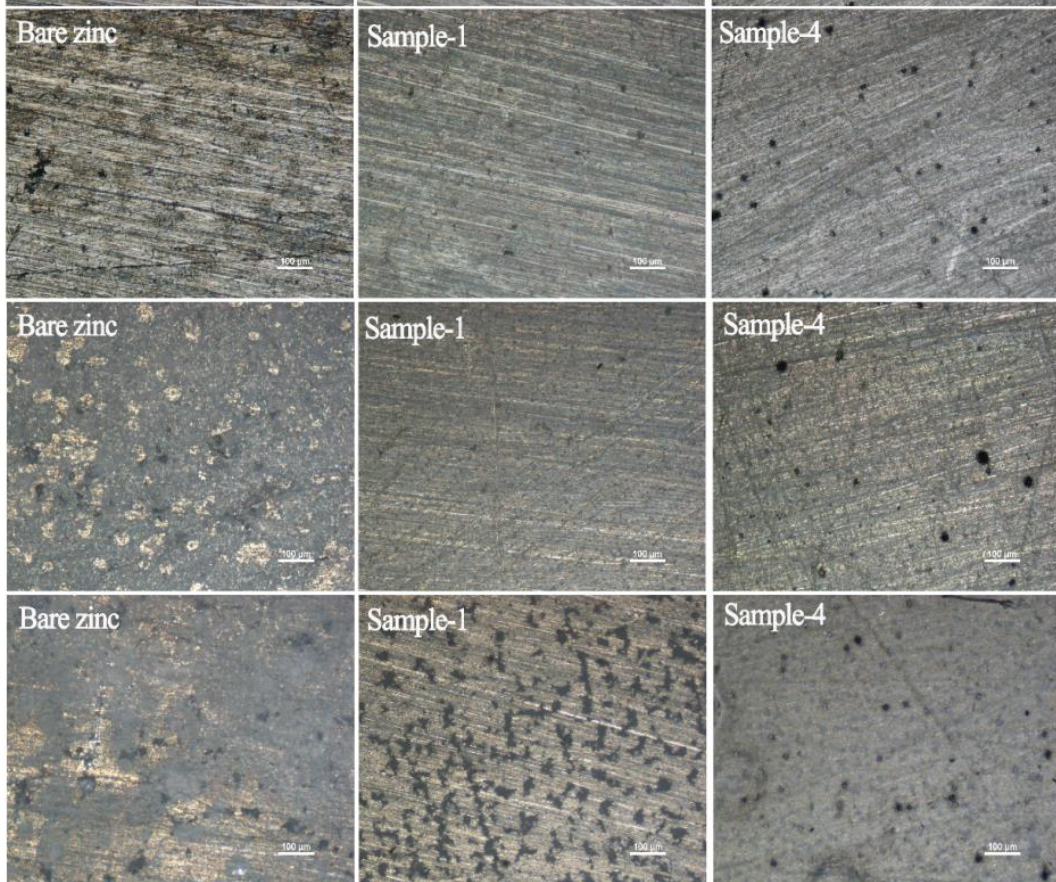

Figure 8. Photograph of bare zinc, PVB coated zinc (Sample 1) and PVB blended with 1.9 wt.\% PNVPY and $2.3 \mathrm{wt} . \%$ CB coated zinc (Sample 4) in different immersion times (a) $0 \mathrm{~h} \mathrm{(b)} 24 \mathrm{~h} \mathrm{(c)} 48 \mathrm{~h}$ (d) $168 \mathrm{~h}$. The specimens were tested in $3.5 \% \mathrm{NaCl}$ solution at room temperature $\left(25^{\circ} \mathrm{C}\right)$.

\subsection{Anti-Corrosion Mechanism Discussion}

Compared to the coating with pure PVB, PNVPY/CB/PVB composite coatings exhibit superior anti-corrosion properties in both physical barrier and chemistry protection as investigated above. It is inferred that organic coatings possess the ability to prevent ion penetration. The PNVPY and CB nanoparticles act as a physical barrier against the chloride ion and oxygen penetrating to the metal surface. Anodic protection by electronic barrier effect is one of the most important factors for metal anticorrosion.

Based on the morphology analysis of the cross section of the PNVPY/CB/PVB coating exfoliation from the coated zinc (Sample 4) as shown in Figure 3, the schematic diagram of the corrosion mechanism is drafted in Figure 9. CPs have strong oxidation potential on the zinc surface. As a result, well-dispersed sulfate doped PNVPY will release doped anions and accept electrons when corrosion occurred, intercepting electron transport between metal surface and electrolyte [36]. CB acts as a bridge between the PNVPY nanoparticles and zinc to ensure the electronic contact and transfer. Besides, PNVPY shifts the reaction site of oxygen reduction from metal/polymer interface (interface I) into the polymer/electrolyte interface (interface II) [37,38]. At the moment, the concentration of oxygen and water is gradually decreasing from interface II to interface I. Therefore, the corrosion rate of the zinc surface is slowed down to achieve the purpose of protection. 

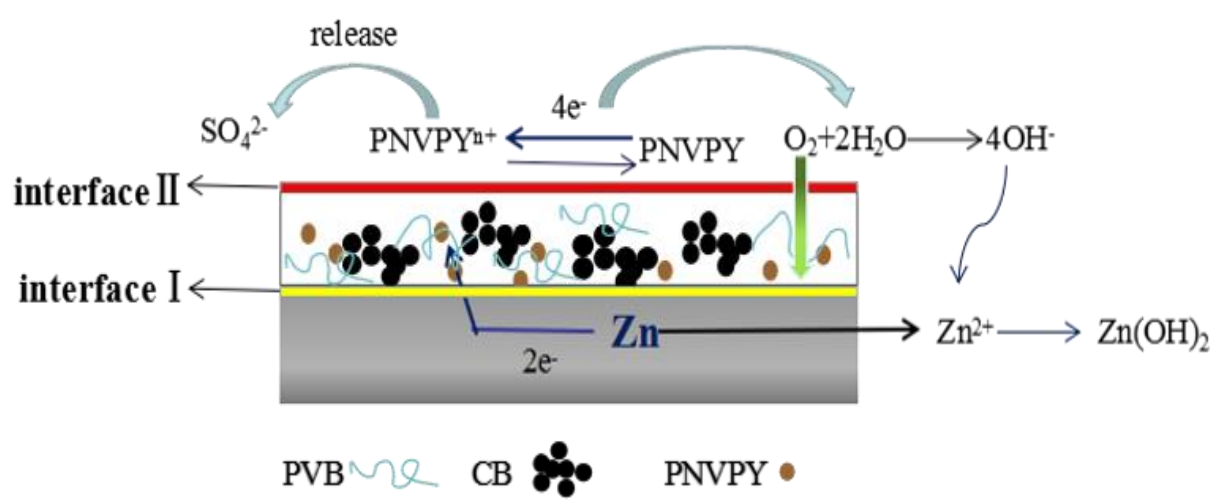

Figure 9. The illustration of the corrosion mechanism of the PNVPY/CB/PVB composite coating.

\section{Conclusions}

In conclusion, to achieve high corrosion resistance of zinc, an environment friendly and easy produced PNVPY/CB/PVB composite coating is obtained. The anti-corrosion properties of the coatings with different content of conductive filler were evaluated using OCP, EIS, and potentiodynamic polarization techniques by immersing them into a $3.5 \% \mathrm{NaCl}$ solution at $25{ }^{\circ} \mathrm{C}$. The electrochemical measurements revealed that the PVB coating with $1.9 \mathrm{wt} . \%$ PNVPY and $2.3 \mathrm{wt} . \%$ $\mathrm{CB}$ significantly improves the corrosion resistance properties of zinc and shows a maximum corrosion protection efficiency up to $99.99 \%$. The immersion results reveal that this coating restrains the spread of corrosion and forms a superior anti-corrosive coating for zinc, while both bare zinc and PVB coated zinc, however, show a severe corrosion for $148 \mathrm{~h}$ in $3.5 \% \mathrm{NaCl}$ solution.

Author Contributions: Conceptualization, D.Y. and L.H.; Methodology, L.H., G.L. and Y.Z.; Software, L.H. and G.L.; Validation, L.H., K.Z. and M.D.; Formal Analysis, D.Y.; Investigation, D.Y.; Resources, D.Y.; Data Curation, L.H.; Writing-Original Draft Preparation, L.H., G.L., Y.Z. and Y.L.; Writing-Review \& Editing, D.Y. and L.H.; Visualization, D.Y.; Supervision, D.Y.; Project Administration, D.Y.; Funding Acquisition, D.Y.

Funding: The research was financially supported by NSFC under Grant No. 51473133, the International Cooperation project of Shaanxi province of 2015KW-016 and the China National 973 Program under Grant No. 2009CB 724202.

Conflicts of Interest: The authors declare no conflict of interest.

\section{References}

1. Yao, B.; Wang, G.; Ye, J.; Li, X. Corrosion inhibition of carbon steel by polyaniline nanofibers. Mater. Lett. 2008, 62, 1775-1778. [CrossRef]

2. Aramaki, K. Treatment of zinc surface with cerium(III) nitrate to prevent zinc corrosion in aerated $0.5 \mathrm{M}$ $\mathrm{NaCl}$. Corros. Sci. 2001, 43, 2201-2215. [CrossRef]

3. Magalhães, A.A.O.; Margarit, I.C.P.; Mattos, O.R. Molybdate conversion coatings on zinc surfaces. J. Electroanal. Chem. 2004, 572, 433-440. [CrossRef]

4. Tsai, C.Y.; Liu, J.; Chen, P. A two-step roll coating phosphate/molybdate passivation treatment for hot-dip galvanized steel sheet. Corros. Sci. 2010, 52, 3385-3393. [CrossRef]

5. Silva, C.G.; Margarit-Mattos, I.C.P.; Mattos, O.R. The molybdate-zinc conversion process. Corros. Sci. 2009, 51, 151-158. [CrossRef]

6. Armelin, E.; Álvaro, M.; Ferreira, C.A.; Alemán, C. Polyaniline, polypyrrole and poly(3,4-ethylenedioxythiophene) as additives of organic coatings to prevent corrosion. Surf. Coat. Technol. 2009, 203, 3763-3769. [CrossRef]

7. Elhalawany, N.; Mossad, M.A.; Zahran, M.K. Novel water based coatings containing some conducting polymers nanoparticles (CPNs) as corrosion inhibitors. Prog. Org. Coat. 2014, 77, 725-732. [CrossRef]

8. Gonzalez-Rodriguez, J.G.; Lucio-García, M.A.; Nicho, M.E.; Cruz-Silva, R.; Casales, M.; Valenzuela, E. Improvement on the corrosion protection of conductive polymers in pemfc environmets by adhesives. J. Power Sources 2007, 168, 184-189. [CrossRef] 
9. De Berry, D.W. Modification of the electrochemical and corrosion behavior of stainless steels with an electroactive coating. J. Electrochem. Soc. 1985, 132, 1022-1026. [CrossRef]

10. Syed, J.A.; Lu, H.; Tang, S. Enhanced corrosion protective PANI-PAA/PEI multilayer composite coatings for 316SS by spin coating technique. Appl. Surf. Sci. 2015, 325, 160-169. [CrossRef]

11. Wang, L.X.; Li, X.G.; Yang, Y.L. Preparation, properties and applications of polypyrroles. React. Funct. Polym. 2007, 47, 125-139. [CrossRef]

12. Yuan, Y.J.; Adelojus, B.; Wallaee, G.G. In situ electrochemical studies on the redox properties of polypyrrole in aqueous solutions. Eur. Polym. J. 1999, 35, 1761-1772. [CrossRef]

13. Jakubiec, B.; Marois, Y.; Zhang, Z. In vitro cellular response to polypyrrole-coated woven polyester fabrics: Potential benefits of electrical conductivity. J. Biomed. Mater. Res. 1998, 41, 519-526. [CrossRef]

14. Ryu, H.; Sheng, N.; Ohtsuk, T.; Fujita, S.; Kajiyama, H. Polypyrrole Film on 55\% Al-Zn-Coated Steel for Corrosion Prevention. Corros. Sci. 2012, 56, 67-77. [CrossRef]

15. Ruhi, G.; Bhandari, H.; Dhawan, S.K. Designing of corrosion resistant epoxy coatings embedded with polypyrrole/ $\mathrm{SiO}_{2}$ composite. Prog. Org. Coat. 2014, 77, 1484-1498. [CrossRef]

16. Rohwerder, M.; Michalik, A. Conducting polymers for corrosion protection: What makes the difference between failure and success? Electrochim. Acta 2007, 53, 1300-1313. [CrossRef]

17. Deshpande, P.P.; Jadhav, N.G.; Gelling, V.J.; Sazou, D. Conducting polymers for corrosion protection: A review. J. Coat. Technol. Res. 2014, 11, 473-494. [CrossRef]

18. Michalik, A.; Rohwerder, M. Conducting polymers for corrosion protection: A critical view. Z. Phys. Chem. 2005, 219, 1547-1559. [CrossRef]

19. Rohwerder, M.; Isik-Uppenkamp, S.; Amarnath, C.A. Application of the Kelvin Probe method for screening the interfacial reactivity of conducting polymer based coatings for corrosion protection. Electrochim. Acta 2011, 56, 1889-1893. [CrossRef]

20. Vimalanandan, A.; Lv, L.P.; Tran, T.H.; Landfester, K.; Crespy, D.; Rohwerder, M. Redox-responsive self-healing for corrosion protection. Adv. Mater. 2013, 25, 6980-6984. [CrossRef] [PubMed]

21. Bai, X.; Tran, T.H.; Yu, D.; Vimalanandan, A.; Hu, X.; Rohwerder, M. Novel conducting polymer based composite coatings for corrosion protection of zinc. Corros. Sci. 2015, 95, 110-116. [CrossRef]

22. Zhang, S.; Zhu, K.; Lv, G.; Wang, G.; Yu, D.; Shao, J. UV-Catalytic Preparation of Polypyrrole Nanoparticles Induced by $\mathrm{H}_{2} \mathrm{O}_{2}$. J. Phys. Chem. C 2015, 119, 18707-18718. [CrossRef]

23. Hao, L.; Zhu, K.; Zhang, S.; Yu, D. The green preparation of poly N-vinylpyrrole nanoparticles. RSC Adv. 2016, 6, 90354-90359. [CrossRef]

24. Wang, J.; Neoh, K.G.; Kang, E.T. Comparative study of chemically synthesized and plasma polymerized pyrrole and thiophene thin films. Thin Solid Films 2004, 446, 205-217. [CrossRef]

25. Pruna, A.; Pilan, L. Electrochemical study on new polymer composite for zinc corrosion protection. Compos. Part B Eng. 2012, 43, 3251-3257. [CrossRef]

26. Kloprogge, J.; Wharton, D.; Hickey, L.; Frost, R.L. Infrared and Raman study of interlayer anions $\mathrm{CO}_{3}{ }^{2-}$, $\mathrm{NO}_{3}{ }^{-}, \mathrm{SO}_{4}{ }^{2-}$ and $\mathrm{ClO}_{4}{ }^{-}$in $\mathrm{Mg}$ /Al-hydrotalcite. Am. Miner. 2002, 87, 623-629. [CrossRef]

27. Ren, S. Electrochemically prepared poly (3-methylthiophene) films for passivation of 430 stainless steel. J. Electrochem. Soc. 1992, 139, 69-74. [CrossRef]

28. Yağan, A.; Pekmez, N.Ö.; Yildiz, A. Electrochemical synthesis of poly (N-methylaniline) on an iron electrode and its corrosion performance. Electrochim. Acta 2008, 53, 5242-5251. [CrossRef]

29. Sherif, E.S.M. Fabrication of various epoxy coatings for offshore applications and evaluating their mechanical properties and corrosion behavior. Int. J. Electrochem. Sci. 2013, 8, 3121-3131.

30. Iroh, J.O.; Su, W. Corrosion performance of polypyrrole coating applied to low carbon steel by an electrochemical process. Electrochim. Acta 2000, 46, 15-24. [CrossRef]

31. Wessling, B. Scientific and commercial breakthrough for organic metals. Synth. Met. 1997, 85, $1313-1318$. [CrossRef]

32. Nguyen, T.D.; Nguyen, T.A.; Pham, M.C.; Piro, B.; Normand, B.; Takenouti, H. Mechanism for protection of iron corrosion by an intrinsically electronic conducting polymer. J. Electroanal. Chem. 2004, 572, 225-234. [CrossRef]

33. Song, Y.K.; Mansfeld, F. Development of a molybdate-phosphate-silane-silicate (MPSS) coating process for electrogalvanized steel. Corros. Sci. 2006, 48, 154-164. [CrossRef]

34. Machnikova, E.; Pazderova, M.; Bazzaoui, M. Corrosion study of PVD coatings and conductive polymer deposited on mild steel: Part I: Polypyrrole. Surf. Coat. Technol. 2008, 202, 1543-1550. [CrossRef] 
35. Poornima, T.; Nayak, J.; Shetty, A.N. 3,4-Dimethoxybenzaldehydethiosemicarbazone as corrosion inhibitor for aged $18 \mathrm{Ni} 250$ grade maraging steel in $0.5 \mathrm{M}$ sulfuric acid. J. Appl. Electrochem. 2011, 41, 223-233. [CrossRef]

36. Sathiyanarayanan, S.; Muthukrishnan, S.; Venkatachari, G. Performance of polyaniline pigmented vinyl acrylic coating on steel in aqueous solutions. Prog. Org. Coat. 2006, 55, 5-10. [CrossRef]

37. Kinlen, P.J.; Silverman, D.C.; Jeffreys, C.R. Corrosion protection using polyaniline coating formulations. Synth. Met. 1997, 85, 1327-1332. [CrossRef]

38. Schauer, T.; Joos, A.; Dulog, L.; Eisenbach, C.D. Protection of iron against corrosion with polyaniline primers. Prog. Org. Coat. 1998, 33, 20-27. [CrossRef]

(C) 2018 by the authors. Licensee MDPI, Basel, Switzerland. This article is an open access article distributed under the terms and conditions of the Creative Commons Attribution (CC BY) license (http://creativecommons.org/licenses/by/4.0/). 